\title{
Intercomparison of Hantzsch and fiber-laser-induced-fluorescence formaldehyde measurements
}

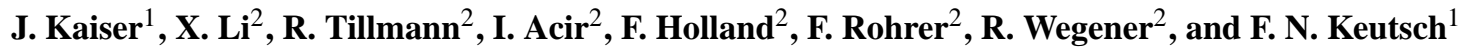 \\ ${ }^{1}$ Department of Chemistry, University of Wisconsin-Madison, Madison, WI, USA \\ ${ }^{2}$ Institut für Energie- und Klimaforschung, Troposphäre (IEK-8), Forschungszentrum Jülich, Jülich, Germany \\ Correspondence to: J. Kaiser (jen.b.kaiser@gmail.com)
}

Received: 17 December 2013 - Published in Atmos. Meas. Tech. Discuss.: 14 January 2014

Revised: 8 April 2014 - Accepted: 24 April 2014 - Published: 4 June 2014

\begin{abstract}
Two gas-phase formaldehyde (HCHO) measurement techniques, a modified commercial wet-chemical instrument based on Hantzsch fluorimetry and a custombuilt instrument based on fiber laser-induced fluorescence (FILIF), were deployed at the atmospheric simulation chamber SAPHIR (Simulation of Atmospheric PHotochemistry In a large Reaction Chamber) to compare the instruments' performances under a range of conditions. Thermolysis of para-HCHO and ozonolysis of 1-butene were used as $\mathrm{HCHO}$ sources, allowing for calculations of theoretical HCHO mixing ratios. Calculated HCHO mixing ratios are compared to measurements, and the two measurements are also compared. Experiments were repeated under dry and humid conditions ( $\mathrm{RH}<2 \%$ and $\mathrm{RH}>60 \%)$ to investigate the possibility of a water artifact in the FILIF measurements. The ozonolysis of 1-butene also allowed for the investigation of an ozone artifact seen in some Hantzsch measurements in previous intercomparisons. Results show that under all conditions the two techniques are well correlated $\left(R^{2} \geq 0.997\right)$, and linear regression statistics show measurements agree with within stated uncertainty ( $15 \%$ FILIF $+5 \%$ Hantzsch). No water or ozone artifacts are identified. While a slight curvature is observed in some Hantzsch vs. FILIF regressions, the potential for variable instrument sensitivity cannot be attributed to a single instrument at this time. Measurements at low concentrations highlight the need for a secondary method for testing the purity of air used in instrument zeroing and the need for further FILIF White cell outgassing experiments.
\end{abstract}

\section{Introduction}

Typical tropospheric formaldehyde (HCHO) concentrations range from $100 \mathrm{ppt}$ in remote polar regions to $20 \mathrm{ppb}$ in urban areas (e.g., Sumner et al., 2002; Dasgupta et al., 2005). Concentrations well below $100 \mathrm{ppt}$ have been observed in the upper troposphere (Fried et al., 2008). Sources of HCHO include primary emissions from anthropogenic activities, biomass burning, and importantly, the oxidation of anthropogenic and biogenic volatile organic compounds (VOCs). The oxidation of VOCs is linked to the formation of secondary pollutants such as secondary organic aerosol and ozone $\left(\mathrm{O}_{3}\right)$. Not only is $\mathrm{HCHO}$ a product of VOC oxidation, but it also is a major source of the $\mathrm{HO}_{\mathrm{x}}\left(\mathrm{HO}_{\mathrm{x}}=\mathrm{OH}+\mathrm{HO}_{2}\right)$ radicals that drive the atmosphere's oxidative capacity (Seinfeld and Pandis, 2006). Accurate and precise measurements of HCHO are therefore necessary to test models of the oxidation mechanisms that form secondary pollutants.

Several measurement techniques for detection of atmospheric HCHO have been developed. These include solution-phase chemical techniques such as 2,4dinitrophenylhydrazine (DNPH) derivatization followed by gas chromatography or high pressure liquid chromatography, the coil enzyme (CENZ) fluorometric method, and Hantzsch derivatization followed by fluorimetry (Heard, 2006, and references therein). In efforts to improve time resolution and avoid the scrubbing process, spectroscopic techniques such as Fourier transform infrared spectroscopy (FTIR), differential optical absorption spectroscopy (DOAS), tunable diode laser absorption spectroscopy (TDLAS), and laser induced fluorescence (LIF) have also been developed (Heard, 2006, and references therein; Hottle et al., 2009). 
When corrected for humidity effects, proton-transfer mass spectrometry (PTR-MS) has also shown to be a promising method for ambient HCHO measurements (Warneke et al., 2011). However, these same humidity effects also decrease the sensitivity of the technique and introduce a variable sensitivity.

Gilpin et al. (1997) carried out an extensive intercomparison of six different HCHO measurement techniques, including a Hantzsch approach and TDLAS. When normalized to formaldehyde standards employed during manifold spiking tests, matched ambient measurements between the Hantzsch and a TDLAS yielded an average ratio of $1.00 \pm 0.11$ over $45 \mathrm{~h}$ of measurement. Additionally, a formal blind intercomparison between two Hantzsch instruments, BroadbandDOAS, DNPH-HPLC, and PTR-MS was performed at the atmospheric simulation chamber SAPHIR (Simulation of Atmospheric PHotochemistry In a large Reaction Chamber) (Wisthaler et al., 2008). Aside from a few reported analytical issues, the agreement between all four techniques was reported as fair. Notably, one Hantzsch instrument (Methanalyser, Alpha Omega Power Technologies, Model MA-100, Albuquerque, New Mexico, USA) equipped with a modified inlet was affected by a non-constant offset. It was further concluded that a different Hantzsch instrument (AL4021, Aerolaser $\mathrm{GmbH}$, Garmisch-Partenkirchen, Germany) was affected by a negative ozone bias during part of the intercomparison. Finally, a recent intercomparison between a Hantzsch instrument built in-house and a commercial PTRMS (IoniconAnalytik GmbH, Innsbruck, Austria) at a rural site in Ontario found the two techniques agreed within 5\% (Vlasenko et al., 2010). Significant scatter for mixing ratios below $1.5 \mathrm{ppb}$ was observed, but not attributed to either technique specifically.

While the fiber laser-induced fluorescence (FILIF) instrument has been deployed on several field campaigns (e.g., DiGangi et al., 2011, 2012; Ahlm et al., 2012; Li et al., 2014), it has only been compared with a time of flight protontransfer mass spectrometer (PTR-TOF-MS) during the Biohydro-atmosphere interactions of Energy, Aerosols, Carbon, $\mathrm{H}_{2} \mathrm{O}$, Organics and Nitrogen - Rocky Mountain Organic Carbon Study (BEACHON-ROCS) in the summer of 2010. For both instruments, a large uncertainty of $30-50 \%$ is reported. While the two measurements were well correlated $\left(R^{2}=0.72\right)$, the FILIF measurements were a factor of 2 less than PTR-TOF-MS measurements. Authors note PTR-TOFMS measurements provide an upper limit of formaldehyde mixing ratios, as interferences may occur from species which fragment to $m / z 31.0177$. However, the largest uncertainty was attributed to calibration methods that were not cross calibrated.

To better understand the poor agreement between PTRTOF-MS and FILIF measurements at BEACHON, a Hantzsch instrument and FILIF were deployed at the SAPHIR chamber for a four-part intercomparison. The same FILIF calibration source was used during this intercomparison and the BEACHON campaign to minimize instrumental differences between the two studies. As Hantzsch measurements have been shown to agree well with spectroscopic techniques and PTR-MS, a comparison between FILIF and Hantzsch provides a secondary check on the accuracy of the FILIF technique. Furthermore, controlled chamber settings allow for calculation of theoretical $\mathrm{HCHO}$ mixing ratios, providing another assessment of instrument accuracy.

An additional goal of the intercomparison was to examine the possibility of a water vapor artifact for FILIF. As water quenches fluorescence more efficiently than nitrogen, the theoretical sensitivity of FILIF is lower under high relative humidity (RH). Indeed, other fluorescence-based measurements apply an RH-dependent calibration to correct for this difference in observed fluorescence signal due to higher quenching (e.g., Schlosser et al., 2009). Previously, lab-based $\mathrm{RH}$-dependent calibrations have been performed to test for water interference for FILIF (DiGangi, 2012). HCHO fluorescence was monitored at $\mathrm{RH}$ ranging from $0 \%$ to $73 \%$ and a constant temperature $\left(19^{\circ} \mathrm{C}\right)$. An enhanced background signal was observed with increasing $\mathrm{RH}$, and this was assumed to be indicative of dissolved HCHO in the water used to humidify the sample. Provided the background signal was subtracted, there was no significant deviation in HCHO concentrations at different humidities, indicating no significant water artifact for HCHO LIF. This conclusion is limited by the assumption that the water used to humidify the airstream contained dissolved HCHO. By comparing the Hantzsch and FILIF measurements under low and high RH conditions, the conclusion that any RH-dependence is negligible can be tested. Furthermore, by using two sources of formaldehyde in the SAPHIR chamber, either thermolysis of para-HCHO or ozonolysis of 1-butene, the previous ozone artifact seen in some Hantzsch measurements can be assessed.

\section{Instrument descriptions}

\subsection{Fiber laser-induced fluorescence}

The FILIF instrument has been described in detail elsewhere (Hottle et al., 2009; DiGangi et al., 2011), but will be briefly discussed here. The beam from a $20 \mathrm{~mW}, 353 \mathrm{~nm}$ tunable, pulsed, narrow-bandwidth laser (NovaWave Technologies, TFL Series) is directed into a 32-pass White-type cell. The resulting fluorescence from $\mathrm{HCHO}$ from 390 to $500 \mathrm{~nm}$ is focused into a photomultiplier tube. The output beam from the White cell is directed into a glass cell containing high concentrations of gas phase $\mathrm{HCHO}$ for wavelength reference. The laser wavelength was scanned over the fluorescence feature every $90 \mathrm{~s}$, and the laser was dithered on and off the rovibronic absorption line for $700 \mathrm{~ms}$ and $300 \mathrm{~ms}$, respectively. The HCHO mixing ratio is proportional to the difference between the fluorescence signal observed when the laser is on 
and off the absorption feature, as well as the laser power. As the observed fluorescence signal is a linear rather than quadratic function of laser power, we can exclude the possibility of laser-generated HCHO in the measurement cell.

FILIF calibrations were performed for each experiment using a HCHO permeation tube (VICI Metronics, 100-0442300-U45) heated to $85^{\circ} \mathrm{C}$ in a portable calibration gas generator (VICI Metronics, Model 120). The permeation source has been characterized using Fourier transform infrared spectroscopy, as described elsewhere (DiGangi et al., 2011). The FILIF calibration is valid as long as the alignment is constant (i.e., as long as the instrument stays in one location) and the laser is tuned to the same fluorescence feature. Typically, the same feature is used throughout a campaign and one calibration factor can be applied to all acquired data. For the final three days of the intercomparison, all calibrations performed agreed within $3.5 \%$. Due to uncharacteristic fluctuations in the laser's accessible wavelength range, a spectral feature different from the feature used during the rest of the campaign was used on the first day of the intercomparison, resulting in a $5 \%$ larger sensitivity for this day.

During the intercomparison, $1 \sigma$ precision derived from measurements of synthetic air was $\sim 20 \mathrm{ppt}$ in $1 \mathrm{~s}$. Above $3 \mathrm{ppb}$, precision is a function of the observed signal derived from the standard deviation of the measurement at a constant concentration. Accuracy was $15 \%$ as limited by the permeation tube calibration. Calibrations were performed up to concentrations of $4 \mathrm{ppb}$, and linear extrapolation was assumed for higher concentrations. This linearity assumption was verified in later lab-based experiments in which successive dilutions of a concentrated HCHO standard (Scott/Air Liquide, $\sim 11 \mathrm{ppm}$ ) in synthetic air were measured. The linear fit of signal to concentration in the $0-4$ ppb range was not statistically different from the fit over the entire concentration range (0-20 ppb).

Chamber air was sampled at $6 \mathrm{~L} \mathrm{~min}^{-1}$ through $\sim 10 \mathrm{~m}$ of $4 \mathrm{~mm}$ I.D. PFA Teflon tubing and a $5 \mu \mathrm{m}$ Teflon particle filter. Previous studies have shown inlet effects for configurations of this nature are negligible (Wert et al., 2002). Instrument zeros performed by overflowing the inlet either with or without the particle filter and tubing agreed within $30 \mathrm{ppt}$. In contrast to previous deployments of this instrument, sample air was used both as the bulk flow through the White cell and to purge the volumes of the white cell not in the detection volume.

During the intercomparison, uncharacteristically rapid and large fluctuations in laser power and wavelength were observed, adding high uncertainty to FILIF measurements. This data is excluded from the analysis, as it does not reflect typical in-field operations of the FILIF instrument.

\subsection{Hantzsch fluorimetry}

HCHO measurement by Hantzsch Fluorimetry was performed by a modified commercial instrument (AL4001,
Aerolaser GmbH, Germany) (Kelly and Fortune, 1994). At a controlled flow rate of $1 \mathrm{~L} \mathrm{~min}^{-1}$, the chamber air is sampled through a $L=10 \mathrm{~m}$, O.D. $=1 / 4^{\prime \prime}$ PFA tube into a temperature controlled $\left(12 \pm 0.2{ }^{\circ} \mathrm{C}\right)$ stainless steel stripping coil. In addition, a stripping solution of $0.05 \mathrm{~mol} \mathrm{~L}^{-1} \mathrm{H}_{2} \mathrm{SO}_{4}$ is continuously pumped through the coil at a flow rate of $0.35 \mathrm{~mL} \mathrm{~min}^{-1}$. The liquid flow is continuously monitored by a flow meter (LFM). HCHO in the sampled air is stripped into the liquid phase with an efficiency of $98 \%$ (Krinke, 1999). The formed HCHO solution is then separated from the gas phase and continuously mixed with a Hantzsch reagent $\left(5.6 \mathrm{~mol} \mathrm{~L}^{-1}\right.$ ammonium acetate, $0.16 \mathrm{~mol} \mathrm{~L}^{-1}$ acetic acid, and $0.02 \mathrm{~mol} \mathrm{~L}^{-1}$ acetylacetone). In a continuous flow reactor held at $70^{\circ} \mathrm{C}, \mathrm{HCHO}$ reacts with the Hantzsch reagent forming the dye 3,5-diacetyl-1,4-dihydrolutidine. The dye solution is then illuminated by a phosphor coated mercury lamp. The emitted fluorescence signal is detected by a photomultiplier at $510 \mathrm{~nm}$.

The sensitivity of the instrument is calibrated using liquid HCHO standards. The standards are added to the stripping coil instead of the stripping solution while HCHO-free air is passed through the coil. The calibration is performed at 3 concentration levels of liquid HCHO standards. The concentrations correspond to gas phase mixing ratios of $2 \mathrm{ppb}$, $10 \mathrm{ppb}$, and $35 \mathrm{ppb}$. HCHO-free air is generated by passing the sampled air through a catalyst (Hopkalit, Draeger) at room temperature. The HCHO-free air is also used to determine the baseline signal of the instrument. During the campaign, the Hantzsch instrument was placed in one of the containers below the SAPHIR chamber. The ambient temperature inside the container was kept at $23^{\circ} \mathrm{C}$. Calibrations for the sensitivity of the instrument, as well as for the measured flow rates were performed in the beginning and in the end of the campaign. The determined sensitivities of the instrument differ by less than $2 \%$. The accuracy of the Hantzsch measurements was around $5 \%$, stemming mainly from the uncertainty of the calibration. The $1 \sigma$ precision derived from the HCHO-free air measurements was around $25 \mathrm{ppt}$ in $11 \mathrm{~s}$. The data is recorded every $11 \mathrm{~s}$ as a $2 \mathrm{~min}$ running average.

\subsection{Supporting instrumentation}

In addition to the $\mathrm{HCHO}$ instruments, several additional measurements were recorded during the intercomparison. A summary of the supporting measurements is provided in Table 1.

Notably, $\mathrm{C}_{4} \mathrm{H}_{8}$ measurements were provided in arbitrary units. $\mathrm{C}_{4} \mathrm{H}_{8}$ concentrations used in this analysis were calculated from the known amount of $\mathrm{C}_{4} \mathrm{H}_{8}$ injected and the maximum observed counts. When $\mathrm{H}_{2} \mathrm{O}$ mixing ratio measurements were unavailable, values were calculated from the measured dew point and the observed temperature. During the third day, data from a nearby meteorological station was used for times during which temperature or pressure measurements were not reported. As this data was not available for the second day, the diurnal fit of the first experiment's 
Table 1. Additional measurements accompanying the HCHO intercomparison.

\begin{tabular}{llll}
\hline Species & Technique & Accuracy & $1 \sigma$ Precision \\
\hline $\mathrm{O}_{3}$ & UV Absorption (Ansyco O342M) & $3 \%$ & $1 \mathrm{ppb}$ \\
$\mathrm{H}_{2} \mathrm{O}$ & Cavity Ring-Down Spectroscopy (Picarro G2301) & $0.02 \%$ & $<0.02 \%$ \\
$1-\mathrm{Buten}$ & Proton-Transfer-Reaction Mass Spectrometry & $8 \%$ & $3-4 \%$ \\
$\mathrm{CH}_{4}$ & Cavity Ring-Down Spectroscopy (Picarro G2301) & $<1 \mathrm{ppb}$ & $<1 \mathrm{ppb}$ \\
$j_{\mathrm{HCHO}}$ & Spectral Radiometer & $10 \%$ & $1 \%$ \\
\hline
\end{tabular}

temperature profile was scaled to replace missing values. While temperature and pressure data affect calculated rate constants and therefore modeled $\mathrm{HCHO}$ concentrations, they do not affect the comparison between FILIF and Hantzsch measurements.

\section{Experiments}

The Hantzsch and FILIF inlets were collocated inside the atmospheric simulation chamber SAPHIR. This Teflon-FEP (DuPont) Teflon-walled chamber has a capacity of approximately 270 cubic meters. Its retractable roof allows the comparison to take place under either ambient lighting or in dark conditions. Further details on the SAPHIR chamber can be found elsewhere (Rohrer et al., 2005; Wegener et al., 2007; Schlosser et al., 2009).

The filling of the chamber and the addition of $\mathrm{HCHO}$ and other species was performed as described in previous intercomparisons detailed by Wisthaler, et al. (2008) and Apel et al. (2008), and is briefly described here. The chamber was flushed with high-purity synthetic air overnight before each experiment. During the experiments, chamber air was diluted as additional synthetic air is added to the chamber to compensate loss from instrument sampling and small leaks in the FEP film. Approximately $2 \mathrm{ppm}$ of methane was added at the start of each experiment to track this dilution. The chamber's mixing fan insured mixing of injected gasses occurred within 3 min.

A summary of each of the four experiments is provided in Table 2. Introduction of $\mathrm{HCHO}$ into the chamber was performed either quickly by thermolysis of para-HCHO powder or more gradually through ozonolysis of 1-butene $\left(\mathrm{C}_{4} \mathrm{H}_{8}\right)$. In the first two experiments, a weighted amount of para-HCHO powder $(3.80 \mathrm{mg}$ on day $1,3.51 \mathrm{mg}$ on day 2 , Merck; purity $>95 \%$ ) was heated in an external glass reactor and swept into the chamber using dry synthetic air. The transfer line was heated to minimize wall loss of HCHO. In the second two experiments, $\mathrm{C}_{4} \mathrm{H}_{8}$ and ozone were injected. To ensure that chemical loss of $\mathrm{C}_{4} \mathrm{H}_{8}$ occurred primarily through reaction with ozone, approximately $500 \mathrm{ppm}$ of $\mathrm{CO}$ was injected as an $\mathrm{OH}$-scavenger. Both the thermolysis and ozonolysis methods were repeated under high and low relative humidity conditions $(\mathrm{RH}>60 \%$ and $<2 \%)$. Water vapor was injected to the chamber prior to the injection of HCHO or 1-butene.

\section{Model calculations}

For all experiments, $\mathrm{HCHO}$ mixing ratios were calculated using a modified 0-D version of the UW-CAFE model (Wolfe and Thornton, 2011) equipped with MCM v 3.2 chemistry (Jenkin et al., 1997; Saunders et al., 2003) using 3 min time steps. For day 1 and 2 experiments, initial HCHO concentrations were calculated from the known mass of para- $\mathrm{HCHO}$ and the chamber volume. For days 3 and $4, \mathrm{O}_{3}$ and $\mathrm{C}_{4} \mathrm{H}_{8}$ measurements were used as model constraints, and $\mathrm{CO}$ mixing ratios were calculated from the known injection amount. For all experiments, the dilution rate constant is calculated from the loss rate of methane, which is assumed to be lost only through dilution. Measured HCHO photolysis frequencies were used during periods of exposure to sunlight. Temperature and relative humidity were also used as model inputs.

As described in Sect. 2.3, a lack of temperature and absolute $\mathrm{C}_{4} \mathrm{H}_{8}$ mixing ratio measurements provide the largest uncertainty in the model calculations. Sensitivity analysis shows a temperature increase of $10^{\circ} \mathrm{C}$ results in a $3 \%$ change in calculated $\mathrm{HCHO}$ mixing ratios. Adjusting $\mathrm{C}_{4} \mathrm{H}_{8}$ by $10 \%$ results in approximately $10 \%$ change in $\mathrm{HCHO}$.

\section{Results and discussion}

For each experiment, we first discuss the agreement of the two instruments according to a linear regression analysis and comparison to the model calculations. All time series data are shown in their original time base ( $1 \mathrm{~s}$ for FILIF, $11 \mathrm{~s}$ for Hantzsch, and $3 \mathrm{~min}$ for model). $\mathrm{H}_{2} \mathrm{O}$ data is not shown when $\mathrm{RH}<2 \%$. The bivariate least squares regressions were computed following the method of York et al. (2004). Because the Hantzsch instrument inherently measures a 2 min rolling average of $\mathrm{HCHO}$ concentrations, the 2 min rolling average of FILIF data is used to provide a comparable measurement for regression analysis. In Sect. 5.5, we discuss possible reasons for deviations from a $1: 1$ fit with a zero intercept, including potential curvature of the regression data and possible baseline artifacts. A summary of the regression statistics is provided in Table 3. 
Table 2. Description of experimental conditions.

\begin{tabular}{lllll}
\hline Experiment & HCHO Source & Max RH (\%) & Periods of Illumination & Other Injected Species \\
\hline Day 1 & Thermolysis of 3.80 mg para-HCHO & 2.0 & $09: 35-10: 20 ; 12: 30-13: 31$ & $\mathrm{CH}_{4}(2.08 \mathrm{ppm})$ \\
Day 2 & Thermolysis of 3.51 mg para-HCHO & 69.5 & $10: 28-11: 36$ & $\mathrm{CH}_{4}(2.15 \mathrm{ppm})$ \\
Day 3 & $72.8 \mathrm{ppb} \mathrm{C}_{4} \mathrm{H}_{8}+200 \mathrm{ppb} \mathrm{O}$ & 0.6 & - & $\mathrm{CH}_{4}(2.50 \mathrm{ppm}) \mathrm{CO}(500 \mathrm{ppm})$ \\
Day 4 & $24.3 \mathrm{ppb} \mathrm{C}_{4} \mathrm{H}_{8}+485 \mathrm{ppb} \mathrm{O}_{3}$ & 79.4 & - & $\mathrm{CH} 4(2.03 \mathrm{ppm}) \mathrm{CO}(500 \mathrm{ppm})$ \\
\hline
\end{tabular}
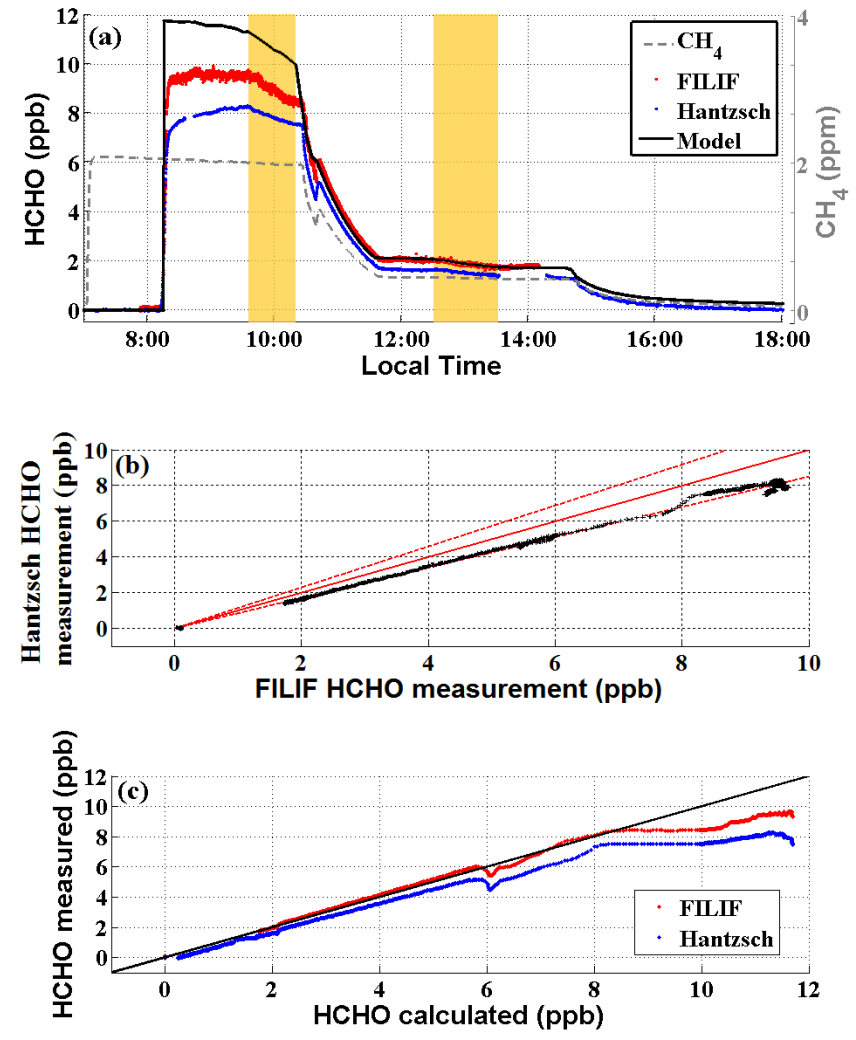

Figure 1. (a) Time series of measured and calculated HCHO mixing ratios as well as the dilution tracer $\left(\mathrm{CH}_{4}\right)$ during day 1 , with periods of illumination denoted by yellow panels. (b) Comparison between $\mathrm{HCHO}$ measurements. Error bars represent $3 \sigma$ precision. Lines represent 1: 1 agreement and $\pm 15 \%$ FILIF measurements. (c) Measurement/model comparison, with the line showing $1: 1$ agreement.

\subsection{Day 1 (dry conditions, Para-HCHO thermolysis)}

The results of the thermolysis of para-HCHO under dry chamber conditions are shown in Fig. 1. Calculated HCHO mixing ratios from $\mathrm{HCHO}$ injection are higher than both sets of measurements. While the causes of the discrepancy between injected standard and measurements at the SAPHIR chamber have not been quantified, such discrepancy is routinely observed. Wisthaler et al. (2008) showed all six HCHO measurements were at least $20 \%$ below calculated values for dry synthetic air studies, similar to the $17 \%$ observed in this study. One possible explanation for the incomplete transfer is insufficient heating of the transfer line results in unaccounted wall loss.

After injection and until the chamber roof is open at $\sim$ 09:30 LT, Hantzsch measurements show gradually increasing HCHO, while model calculations and FILIF measurements show a sharp increase followed by a relatively constant concentration. A gradual increase over this $1.5 \mathrm{~h}$ time frame is unexpected, as SAPHIR was connected to the addition chamber for $\sim 20 \mathrm{~min}$ and the timescale of mixing within the chamber is $\sim 3 \mathrm{~min}$. While heterogeneous chamber mixing would be a plausible explanation for the temporal differences in the Hantzsch and FILIF measurements, the instruments' inlets were located within 6 inches of one another. A strong concentration gradient is not expected to exist for an extended period of time on this spatial scale. Beyond the initial time period, Hantzsch-FILIF agreement was relatively constant.

The quick initial rise in $\mathrm{HCHO}$ is not included in the regression analysis, as deviation from the $1: 1$ line during this time is more indicative of instrument time response and synchronization than measurement accuracy. Excluding this time, linear regression of Hantzsch v. FILIF provides a slope of $0.867 \pm 0.0002$, an intercept of $-0.090 \pm 0.001 \mathrm{ppb}$, and $R^{2}=0.997$. The slope falls within the combined FILIF and Hantzsch accuracies $(15 \%+5 \%)$. The intercept is discussed further in Sect. 5.5.

\subsection{Day 2 (humid conditions, Para-HCHO thermolysis)}

Figure 2 shows the results of the thermolysis of para-HCHO under humid chamber conditions. Again, incomplete transfer of thermolyzed para-HCHO is suspected to cause calculated $\mathrm{HCHO}$ mixing ratios higher than both measurements. FILIF was disconnected from SAPHIR from $\sim 14: 15-16: 30$ LT for calibration. FILIF measurements after the calibration show more significant scatter than earlier measurements, as laser power fluctuated more rapidly during this time.

Notably, FILIF HCHO measurements increase during chamber humidification before $\mathrm{HCHO}$ injection, while Hantzsch measurements stay relatively constant. Hantzsch measurements on day 4 showed a similar increase in $\mathrm{HCHO}$ during chamber humidification (Fig. 4). It is possible that either the water used to humidify the chamber contains some $\mathrm{HCHO}$, or a water-dependent sample line outgassing process is at times observed. This is discussed further in Sect. 5.5. 


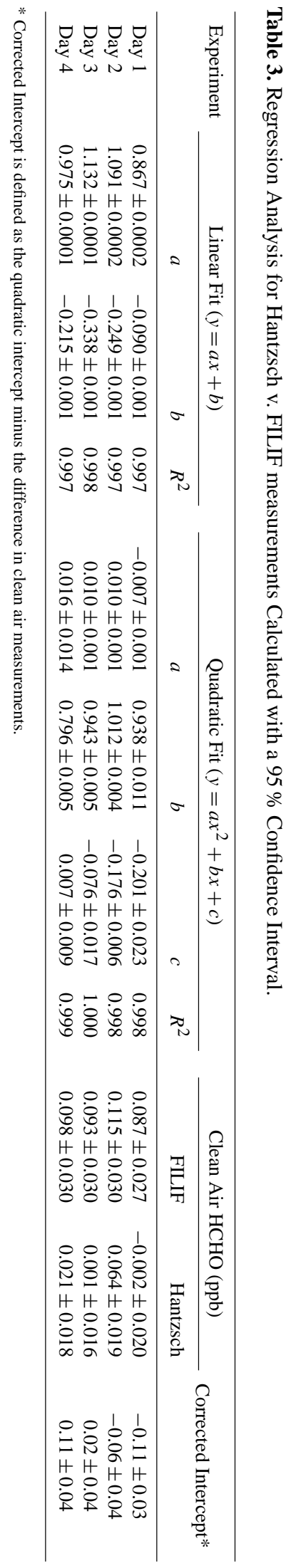

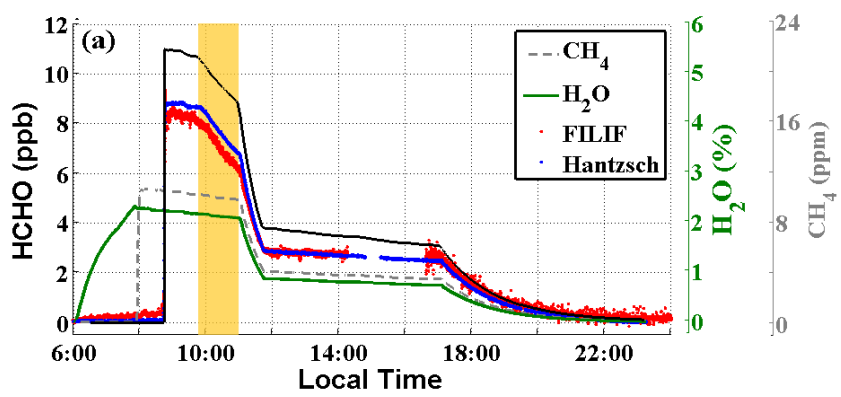
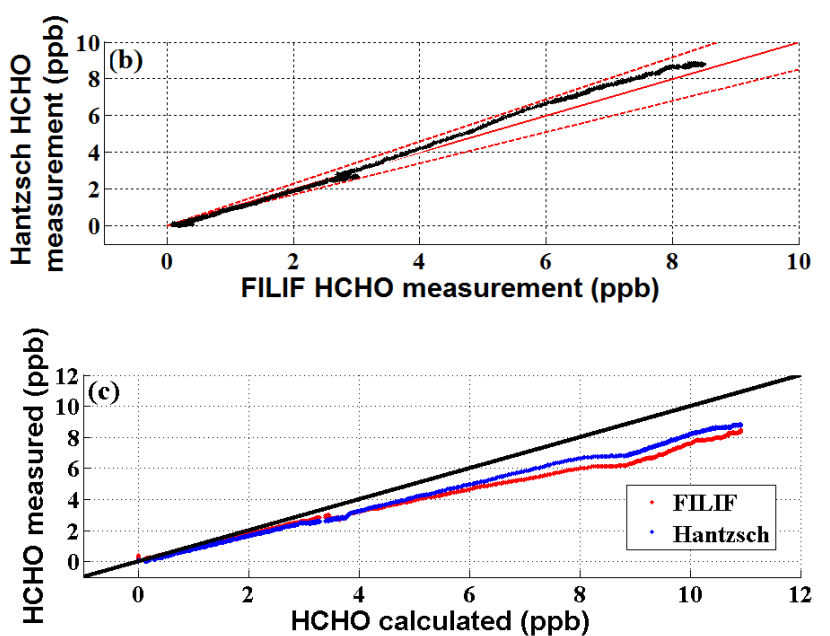

Figure 2. (a) Time series of measured and calculated HCHO mixing ratios, $\mathrm{CH}_{4}$, and $\mathrm{H}_{2} \mathrm{O}$ during day 2, with periods of illumination denoted by yellow panels. (b) Comparison between $\mathrm{HCHO}$ measurements. Error bars represent $3 \sigma$ precision. Lines represent $1: 1$ agreement and $\pm 15 \%$ FILIF measurements. (c) Measurement/model comparison, with the line showing $1: 1$ agreement.

The Hantzsch-FILIF relationship seems to differ slightly from the earlier measurements after reconnection to the chamber, possibly due to Hantzsch baseline drift. Regression analysis over the entire day (again excluding the sharp rise) provides a slope of $1.091 \pm 0.0002$, a $y$ intercept of $-0.249 \pm 0.001 \mathrm{ppb}$, and an $R^{2}$ of 0.997 . Fitting the earlier measurements provides a slope of 1.06 and a $y$ intercept of $0.04 \mathrm{ppb}$, while fitting later measurements yields a slope of 0.989 and a $y$ intercept of $-0.15 \mathrm{ppb}$. The slopes of each time period as well as the entire data set falls within the stated uncertainty of FILIF, indicating no water artifact for the FILIF instrument.

\subsection{Day 3 (dry conditions, $\mathrm{C}_{4} \mathrm{H}_{8}$ ozonolysis)}

The results of the ozonolysis of $\mathrm{C}_{4} \mathrm{H}_{8}$ under dry chamber conditions are shown in Fig. 3. Hantzsch measurements are not available after 13:00 LT due to a malfunctioning zero valve. The regression analysis provides a slope of $1.132 \pm 0.0001, y$ intercept of $-0.338 \pm 0.001 \mathrm{ppb}$, and $R^{2}=0.998$. With the exception of low concentrations where 

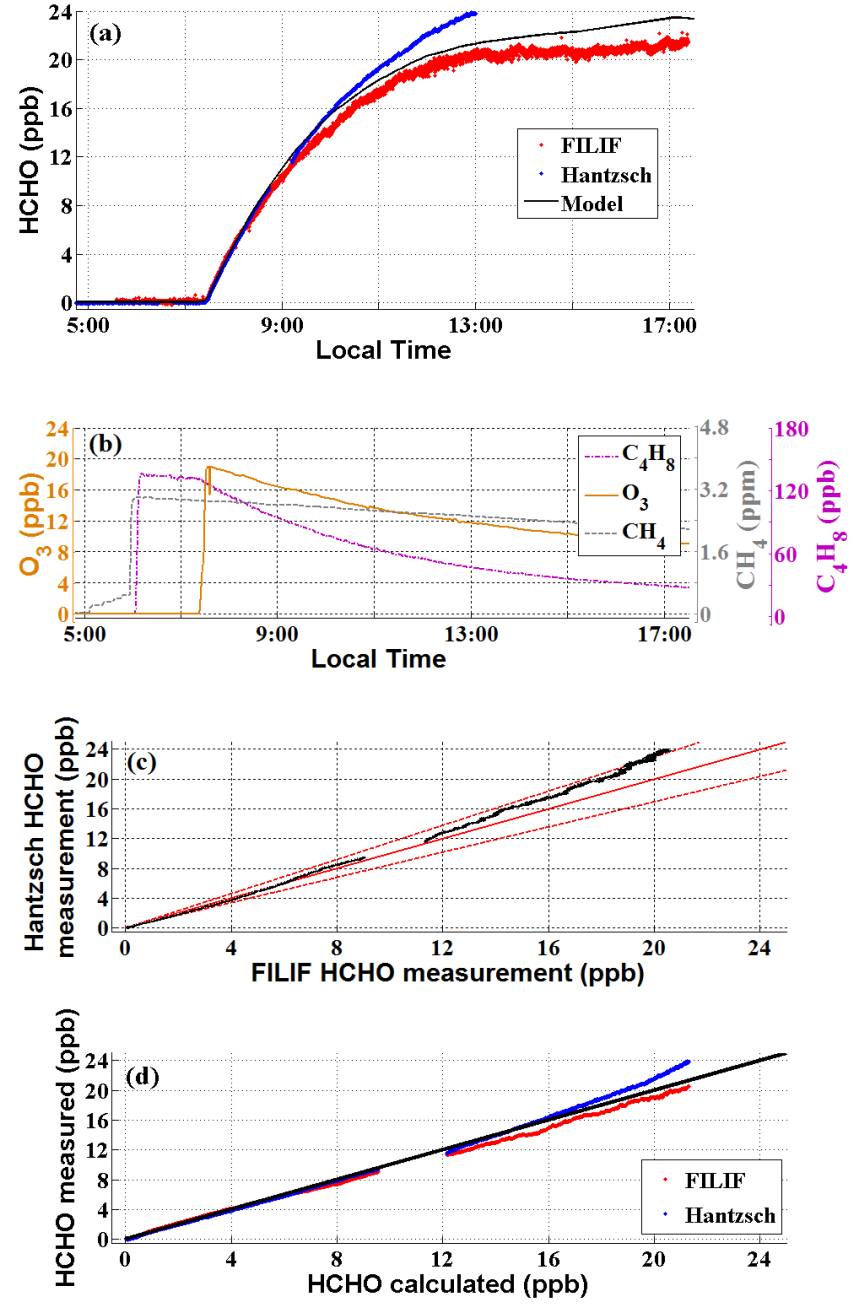

Figure 3. (a) Time series of measured and calculated $\mathrm{HCHO}$ mixing ratios during day 3. (b) Time series of $\mathrm{C}_{4} \mathrm{H}_{8}$, ozone, and $\mathrm{CH}_{4}$. (c) Comparison between $\mathrm{HCHO}$ measurements. Error bars represent $3 \sigma$ precision. Lines represent 1:1 agreement and $\pm 15 \%$ FILIF measurements. (d) Measurement/model comparison, with the line showing $1: 1$ agreement.

instrument offsets become more important (see Sect. 5.5), and at the later times (HCHO $>20 \mathrm{ppb})$, Hantzsch and FILIF measurements fall within $15 \%$ of each other. At this time, we have no explanation for the growing discrepancy between Hantzsch and FILIF observed during this experiment.

\subsection{Day 4 (humid conditions, $\mathrm{C}_{4} \mathrm{H}_{8}$ ozonolysis)}

Figure 4 shows the results of the ozonolysis of $\mathrm{C}_{4} \mathrm{H}_{8}$ under humid chamber conditions. FILIF measurements are not available before $\sim$ 13:00 LT due to fluctuations in laser power and wavelength not typical during field operation. Regression analysis provides a slope of $0.975 \pm 0.0001, y$ intercept of $-0.215 \pm 0.001 \mathrm{ppb}$, and $R^{2}=0.997$. The Hantzsch v. FILIF slope falls between the two slopes observed in the dry-conditions experiment.
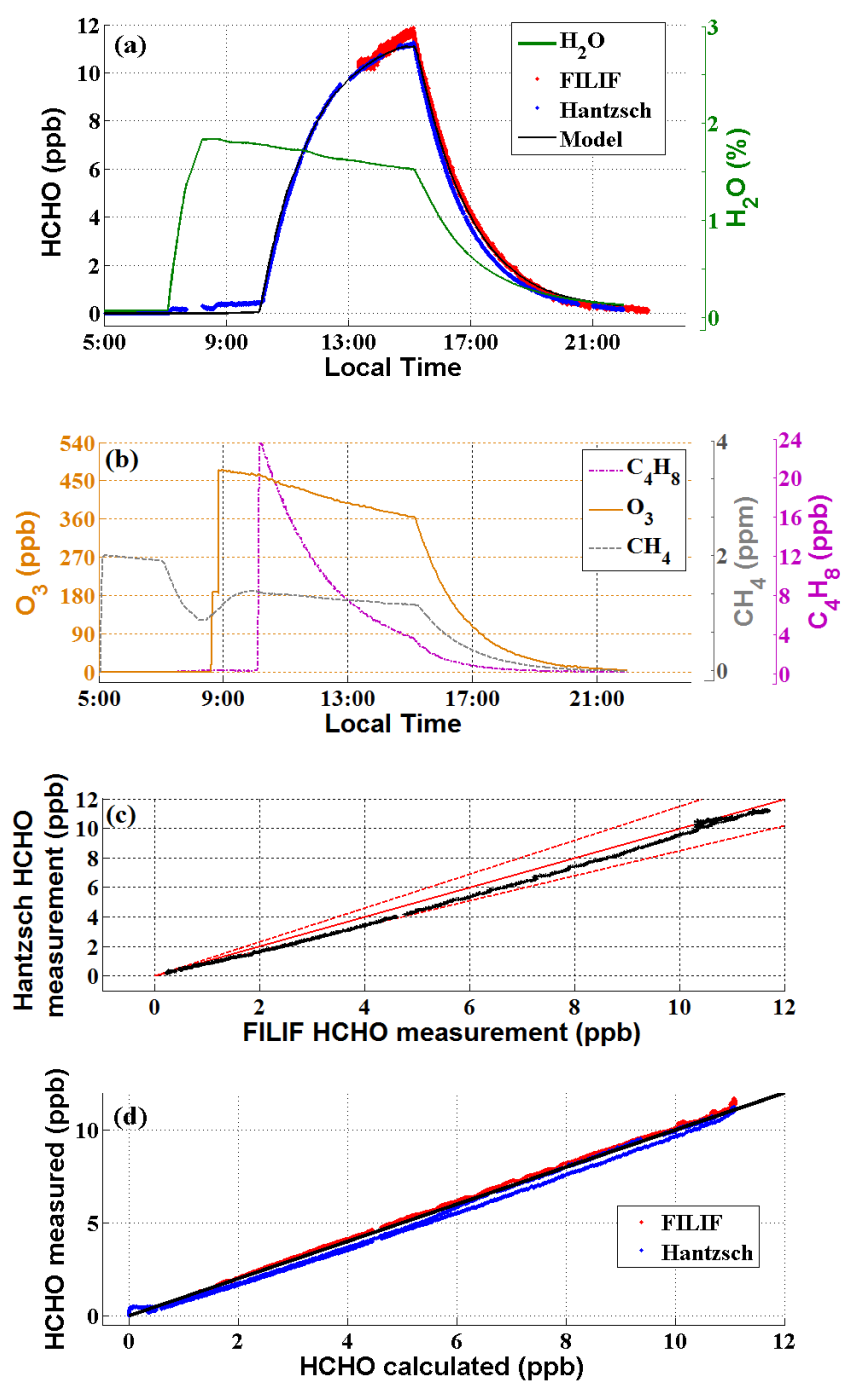

Figure 4. (a) Time series of measured and calculated HCHO mixing ratios and $\mathrm{H}_{2} \mathrm{O}$ during day 4. (b) Time series of $\mathrm{C}_{4} \mathrm{H}_{8}$, ozone, $\mathrm{CH}_{4}$. (c) Comparison between HCHO measurements. Error bars represent $3 \sigma$ precision. Lines represent $1: 1$ agreement and $\pm 15 \%$ FILIF measurements. (d) Measurement/model comparison, with the line showing $1: 1$ agreement.

\subsection{FILIF/Hantzsch instrument offsets and clean air measurements}

As seen in Table 3, a persistent negative intercept was observed in the Hantzsch/FILIF linear regressions. There are several factors to consider when addressing this offset, including instrument baselines, outgassing of either sample lines or the FILIF measurement cell, Hantzsch zeroing frequency, and curvature of the fit.

First, the methods of determining instrument baselines must be considered. The Hantzsch instrument uses scrubbed air to determine the magnitude of the photomultiplier tube (PMT) offset. The reported HCHO is proportional to the 
difference in the PMT signal of the sample air and the PMT signal of the scrubbed air. If any HCHO remains in the scrubbed air, the Hantzsch measurements will be biased by that amount. In contrast, FILIF measurements do not require an empirically defined instrument baseline. Because the spectroscopic signal verified by the reference cell is unique to $\mathrm{HCHO}$, any difference between on-and-off resonance signals is the result of $\mathrm{HCHO}$ in the measurement cell. FILIF consistently measures $\sim 100 \mathrm{ppt} \mathrm{HCHO}$ in clean chamber air, while Hantzsch measures $\sim 0$ ppt. Below, we consider if this trace amount of HCHO measured by FILIF is an artifact of instrument outgassing, or if the clean chamber air truly contains trace amounts of $\mathrm{HCHO}$ not detected by the Hantzsch.

Both the instrument sampling lines and the FILIF White cell are potential sources of outgassing HCHO. Because the Hantzsch and FILIF instruments sample lines were of similar lengths and identical materials, any outgassing of the lines would affect the measurements equally and could not explain the difference between the two measurements. This leaves the possibility that $\mathrm{HCHO}$ from sample air deposits on the walls of the FILIF White cell and then is slowly expelled. The experiments on day 2 suggest this outgassing may be RH dependent, as humidification leads to a much larger increase in FILIF than Hantzsch measurement. However, day 4 Hantzsch measurements show that humidification can cause an increase in $\mathrm{HCHO}$ in the chamber itself. To determine if the rise in $\mathrm{HCHO}$ seen during humidification is internal to the chamber or a result of FILIF White cell outgassing, an investigation of baseline measurements again becomes important.

Because of the aging of peristaltic tubes, stripping solution, and Hantzsch solution, the Hantzsch instrument's baseline is not constant in time, but interpolated or extrapolated from periodic zero measurements. On day 2, a baseline measurement is obtained before chamber humidification, and then again about $9 \mathrm{~h}$ later. The readings are linearly interpolated to provide a uniformly increasing baseline. While it is assumed the change in instrument offset is constant with time, other experiments have shown the baseline does not necessarily drift at a uniform rate. This is especially relevant at high concentrations of $\mathrm{HCHO}$, where the baseline can be affected by insufficient removal of HCHO by the Hopkalit catalyst. If instead we consider a situation where the baseline drift was slow, the first zero measurement would be more representative of the true instrument baseline during chamber humidification. Retaining a constant baseline increases the Hantzsch measurement by 130 ppt to 220 ppt. This is comparable to the $204 \mathrm{ppt}$ observed on day 4 during humidification while the Hantzsch baseline was stable, and within $100 \mathrm{ppt}$ of the FILIF measurement.

At least one instrument on each day shows that humidification can lead to increased HCHO in the SAPHIR chamber. The discrepancy on the second day is either due to a drifting Hantzsch baseline or FILIF White cell outgassing.
Because outgassing has been previously observed in other FILIF measurements (DiGangi et al., 2011), and because the Hantzsch baseline was measured infrequently, we cannot determine with absolute certainty the cause of the discrepancy of zero air measurements on day 2 during chamber humidification.

Finally, we examine the possibility of curvature in the Hantzsch v. FILIF regression analysis. While the linear correlation coefficients are high for all experiments, day 3 clearly shows that a second degree polynomial better represents the observed data (Fig. 3). This slight curvature is the result of either one or both instruments' sensitivity changing over time. Because calibrations performed over the 4 days were in good agreement for both instruments (within $3.5 \%$ for FILIF, $2 \%$ for Hantzsch), and because all calibrations were highly linear even to high concentrations, we cannot attribute the changing sensitivity to either instrument at this time. However, we note that the leading term in the second degree polynomial is small (Table 3 ). For all but the first day, taking the curvature into account brings the intercept closer to zero.

The corrected intercepts considering both the curvature and instrument offsets are shown in the final column of Table 3. To provide a comparison between Hantzsch and FILIF measurements that is not affected by the HCHO measured in clean air by FILIF, we subtract the difference in clean chamber air measurements from the FILIF measurements. Because FILIF was not measuring at the start of day 4 , the average clean chamber air measurement of other experiments is used. The values are much closer to zero than the intercept calculated from linear regression alone; however, a difference of as much as $110 \mathrm{ppt}$ in the corrected intercepts is still observed. A secondary method for testing the purity of air used in instrument zeroing and eliminating the potential for White cell outgassing is vital, as $\mathrm{HCHO}$ mixing ratios in the $0-200$ ppt range have been observed in the field. Similarly, the reasons for the curvature observed on some days requires further study, for example using long-path DOAS as an independent method.

\section{Conclusions}

Comparison between Hantzsch and FILIF HCHO measurements at the atmosphere simulation chamber SAPHIR demonstrated agreement between the two techniques within $15 \%$ and good correlation $\left(R^{2} \geq 0.997\right)$ under all conditions. At low HCHO concentrations $(<400 \mathrm{ppt})$ and at the end of the humid ozonolysis of 1-butene, the difference between the techniques was at times larger than the $15 \%$ accuracy of the FILIF measurements, but within the combined accuracies of the two techniques.

If water vapor were to significantly decrease the sensitivity of the FILIF instrument due to increased fluorescence quenching, the artifact would manifest itself in systematically lower slopes in Hantzsch v. FILIF during humid 
experiments. No such trend is discernible, indicating that this artifact was not identifiable in this intercomparison. An ozone bias for the Hantzsch instrument would yield poor FILIF-Hantzsch agreement for the 1-butene ozonolysis studies. While the dry ozonolysis study had the largest discrepancy from $1: 1$ agreement, the humid ozonolysis study resulted in the best instrument agreement (slope $=0.978$ ). We cannot conclude any discrepancies were a result of ozone artifacts.

The instrument offsets of both of FILIF and Hantzsch requires further careful examination when addressing low concentrations of $\mathrm{HCHO}(<400 \mathrm{ppt})$. As the Hantzsch baseline can vary with time, more frequent zero measurements may be necessary in these regimes. Verifying the purity of synthetic air through a secondary spectroscopic technique would allow us to address the accuracy of FILIF and potential for White cell outgassing under humid conditions.

FILIF and Hantzsch HCHO measurements agree within the stated accuracy over a wide range of experimental conditions. Given the good agreement in previous intercomparisons between the Hantzsch techniques and the PTRMS measurements (Wisthaler et al., 2008), the cause of the factor-of-two disagreement observed between PTR-TOF-MS and FILIF measurements during the BEACHON field campaign is unclear. Possibly, VOCs present during BEACHONROCS but not in the SAPHIR intercomparisons could fragment and produce an ion isomeric with $\mathrm{HCHO}$. An intercomparison between these two techniques under controlled chamber conditions could confirm this hypothesis.

Acknowledgements. This material is based upon work supported by the National Science Foundation Graduate Research Fellowship under Grant No. DGE-1256259. The authors also thank the National Science Foundation (AGS 1051338) for support. We acknowledge the inputs from all participants of the intercomparison study. The authors also thank G. M. Wolfe for technical support with the FILIF instrument, R. Häseler for technical support with SAPHIR and B. Bohn for providing photolysis frequencies. The work was supported by T. Brauers and A. Wahner.

Edited by: D. Heard

\section{References}

Ahlm, L., Liu, S. Day, D. A., Russell, L. M., Weber, R., Gentner, D. R., Goldstein, A. H., DiGangi, J. P., Henry, S. B., Keutsch, F. N., VandenBoer, T.C., Markovic, M. Z., Murphy, J. G., Ren, X. R., and Scheller, S.: Formation and growth of ultrafine particles from secondary sources in Bakersfield, California, J. Geophys. Res., 117, D00V08, doi:10.1029/2011JD017144, 2012.

Apel, E. C., Brauers, T., Koppmann, R., Bandowe, B., Bossmeyer, J., Holzke, C., Tillmann, R., Wahner, A., Wegener, R., Brunner, A., Jocher, M., Ruuskanen, T., Spirig, C., Steigner, D., Steinbrecher, R., Alvarez, E. G., Mueller, K., Burrows, J. P., Schade, G., Solomon, S. J., Ladstaetter-Weissenmayer, A., Simmonds, P., Young, D., Hopkins, J. R., Lewis, A. C., Legreid, G.,
Reimann, S., Hansel, A., Wisthaler, A., Blake, R. S., Ellis, A. M., Monks, P. S., and Wyche, K. P.: Intercomparison of oxygenated volatile organic compound measurements at the SAPHIR atmosphere simulation chamber, J. Geophys. Res., 113, D20307, doi:10.1029/2008JD009865, 2008.

Dasgupta, P. K., Li, J. Z., Zhang, G. F., Luke, W. T., McClenny, W. A., Stutz, J., and Fried, A.: Summertime ambient formaldehyde in live US metropolitan areas: Nashville, Atlanta, Houston, Philadelphia, and Tampa, Environ. Sci. Technol., 39, 4767-4783, doi:10.1021/es048327d, 2005.

DiGangi, J.: Formaldehyde as a Probe of Rural Volatile Organic Compound Oxidation, Ph.d. thesis, University of Wisconsin, Madison, USA, 2012.

DiGangi, J. P., Boyle, E. S., Karl, T., Harley, P., Turnipseed, A., Kim, S., Cantrell, C., Maudlin III, R. L., Zheng, W., Flocke, F., Hall, S. R., Ullmann, K., Nakashima, Y., Paul, J. B., Wolfe, G. M., Desai, A. R., Kajii, Y., Guenther, A., and Keutsch, F. N.: First direct measurements of formaldehyde flux via eddy covariance: implications for missing in-canopy formaldehyde sources, Atmos. Chem. Phys., 11, 10565-10578, doi:10.5194/acp-1110565-2011, 2011.

DiGangi, J. P., Henry, S. B., Kammrath, A., Boyle, E. S., Kaser, L., Schnitzhofer, R., Graus, M., Turnipseed, A., Park, J-H., Weber, R. J., Hornbrook, R. S., Cantrell, C. A., Maudlin III, R. L., Kim, S., Nakashima, Y., Wolfe, G. M., Kajii, Y., Apel, E.C., Goldstein, A. H., Guenther, A., Karl, T., Hansel, A., and Keutsch, F. N.: Observations of glyoxal and formaldehyde as metrics for the anthropogenic impact on rural photochemistry, Atmos. Chem. Phys., 12, 9529-9543, doi:10.5194/acp-12-9529-2012, 2012.

Fried, A., Olson, J., Walega, J., Crawford, J., Chen, G., Weibring, P., Richter, D., Roller, C., Tittel, F., Porter, M., Fuelberg, H., Halland, J., Bertram, T., Cohen, R., Pickering, K., Heikes, B., Snow, J., Shen, H., O'Sullivan, D., Brune, W., Ren, X., Blake, D., Blake, N., Sachse, G., Diskin, G., Podolske, J., Vay, S., Shetter, R., Hall, S., Anderson, B., Thornhill, L., Clarke, A., McNaughton, C., Singh, H., Avery, M., Huey, G., Kim, S., and Millet, D.: Role of convection in redistributing formaldehyde to the upper troposphere over North America and the North Atlantic during the summer 2004 INTEX campaign, J. Geophys. Res.-Atmos., 113, D17306, doi:10.1029/2007JD009760, 2008.

Gilpin, T., Apel, E., Fried, A., Wert, B., Calvert, J., Zhang, G., Dasgupta, P., Harder, J., Heikes, B., Hopkins, B., Westberg, H., Kleindienst, T., Lee, Y., Zhou, X., Lonneman, W., and Sewell, S.: Intercomparison of six ambient $\left[\mathrm{CH}_{2} \mathrm{O}\right]$ measurement techniques, J. Geophys. Res.-Atmos., 102, 21161-21188, doi:10.1029/97JD01314, 1997.

Heard, D. E. (Ed.): Analytical Techniques for Atmospheric Measurement, Blackwell Publishing, ISBN 1405123575, Oxford, UK, 2006.

Hottle, J. R., Huisman, A. J., DiGangi, J. P., Kammrath, A., Galloway, M. M., Coens, K. L., and Keutsch, F. N.: A Laser Induced Fluorescence-Based Instrument for In-Situ Measurements of Atmospheric Formaldehyde, Environ. Sci. Technol., 43, 790-795, doi:10.1021/es801621f, 2009.

Jenkin, M. E., Saunders, S. M., and Pilling, M. J.: The tropospheric degradation of volatile organic compounds: A protocol for mechanism development, Atmos. Environ., 31, 81-104, 1997.

Jenkin, M. E., Saunders, S. M., Wagner, V., and Pilling, M. J.: Protocol for the development of the Master Chemical Mecha- 
nism, MCM v3 (Part B): tropospheric degradation of aromatic volatile organic compounds, Atmos. Chem. Phys., 3, 181-193, doi:10.5194/acp-3-181-2003, 2003.

Kaser, L., Karl, T., Schnitzhofer, R., Graus, M., Herdlinger-Blatt, I. S., DiGangi, J. P., Sive, B., Turnipseed, A., Hornbrook, R. S., Zheng, W., Flocke, F. M., Guenther, A., Keutsch, F. N., Apel, E., and Hansel, A.: Comparison of different real time VOC measurement techniques in a ponderosa pine forest, Atmos. Chem. Phys., 13, 2893-2906, doi:10.5194/acp-13-2893-2013, 2013.

Kelly, T. J. and Fortune, C. R.: Continuous Monitoring of Gaseous Formaldehyde Using an Improved Fluorescence Approach, Int. J. Environ. An. Ch., 54, 249-263, doi:10.1080/03067319408034093, 1994.

Krinke, S.: Experimentelle Bestimmung der Depositionsgeschwindigkeit von Formaldehyd und Ozon über einem Laubwaldbestand, Phd thesis, Universität Stuttgart, 1999.

Li, X., Rohrer, F., Hofzumahaus, A., Brauers, T., Häseler, R., Bohn, B., Broch, S., Fuchs, H., Gomm, S., Holland, F., Jäger, J., Kaiser, J., Keutsch, F. N., Lohse, I., Lu, K., Tillmann, R., Wegener, R., Wolfe, G. M., Mentel, T. F., Kiendler-Scharr, A., and Wahner, A.: Missing Gas-Phase Source of HONO Inferred from Zeppelin Measurements in the Troposphere, Science, 344, 292-296, doi:10.1126/science.1248999, 2014.

Rohrer, F., Bohn, B., Brauers, T., Brüning, D., Johnen, F.-J., Wahner, A., and Kleffmann, J.: Characterisation of the photolytic HONO-source in the atmosphere simulation chamber SAPHIR, Atmos. Chem. Phys., 5, 2189-2201, doi:10.5194/acp-5-21892005, 2005.

Saunders, S. M., Jenkin, M. E., Derwent, R. G., and Pilling, M. J.: Protocol for the development of the Master Chemical Mechanism, MCM v3 (Part A): tropospheric degradation of nonaromatic volatile organic compounds, Atmos. Chem. Phys., 3, 161-180, doi:10.5194/acp-3-161-2003, 2003.

Schlosser, E., Brauers, T., Dorn, H.-P., Fuchs, H., Häseler, R., Hofzumahaus, A., Holland, F., Wahner, A., Kanaya, Y., Kajii, Y., Miyamoto, K., Nishida, S., Watanabe, K., Yoshino, A., Kubistin, D., Martinez, M., Rudolf, M., Harder, H., Berresheim, H., Elste, T., Plass-Dülmer, C., Stange, G., and Schurath, U.: Technical Note: Formal blind intercomparison of $\mathrm{OH}$ measurements: results from the international campaign HOxComp, Atmos. Chem. Phys., 9, 7923-7948, doi:10.5194/acp-9-7923-2009, 2009.
Seinfeld, J. H. and Pandis, S. N: Atmospheric Chemistry and Physics, from Air Pollution to Climate Change, 2nd Edn., John Wiley \& Sons, available at: http://www.knovel.com/web/portal/browse/display?_EXT_ KNOVEL_DISPLAY_bookid=2126\&VerticalID=0, 2006.

Sumner, A. L., Shepson, P. B., Grannas, A. M., Bottenheim, J. W., Anlauf, K. G., Worthy, D., Schroeder, W. H., Steffen, A., Domine, F., Perrier, S., and Houdier, S.: Atmospheric chemistry of formaldehyde in the Arctic troposphere at Polar Sunrise, and the influence of the snowpack, Atmos. Environ., 36, 2553-2562, doi:10.1016/S1352-2310(02)00105-X, 2002.

Vlasenko, A., Macdonald, A. M., Sjostedt, S. J., and Abbatt, J. P. D.: Formaldehyde measurements by Proton transfer reaction - Mass Spectrometry (PTR-MS): correction for humidity effects, Atmos. Meas. Tech., 3, 1055-1062, doi:10.5194/amt-3-1055-2010, 2010.

Warneke, C., Veres, P., Holloway, J. S., Stutz, J., Tsai, C., Alvarez, S., Rappenglueck, B., Fehsenfeld, F. C., Graus, M., Gilman, J. B., and de Gouw, J. A.: Airborne formaldehyde measurements using PTR-MS: calibration, humidity dependence, intercomparison and initial results, Atmos. Meas. Tech., 4, 23452358, doi:10.5194/amt-4-2345-2011, 2011.

Wegener, R., Brauers, T., Koppmann, R., Rodríguez Bares, S., Rohrer, F., Tillmann, R., Wahner, A., Hansel, A., and Wisthaler, A.: Investigation of the ozonolysis of short chained alkenes in the atmosphere simulation chamber SAPHIR, J. Geophys. Res., 112, D13301, doi:10.1029/2006JD007531, 2007.

Wert, B. P., Fried, A., Henry, B., and Cartier, S.: Evaluation of inlets used for the airborne measurement of formaldehyde, J. Geophys. Res.-Atmos., 107, 4163, doi:10.1029/2001jd001072, 2002.

Wisthaler, A., Apel, E. C., Bossmeyer, J., Hansel, A., Junkermann, W., Koppmann, R., Meier, R., Müller, K., Solomon, S. J., Steinbrecher, R., Tillmann, R., and Brauers, T.: Technical Note: Intercomparison of formaldehyde measurements at the atmosphere simulation chamber SAPHIR, Atmos. Chem. Phys., 8, 2189 2200, doi:10.5194/acp-8-2189-2008, 2008.

Wolfe, G. M. and Thornton, J. A.: The Chemistry of AtmosphereForest Exchange (CAFE) Model - Part 1: Model description and characterization, Atmos. Chem. Phys., 11, 77-101, doi:10.5194/acp-11-77-2011, 2011.

York, D., Evensen, N. M., Marinez, M. L., and Delgado, J. D. B.: Unified equations for the slope, intercept, and standard errors of the best straight line, Amer. J. Phys., 72, 367-375, doi:10.1119/1.1632486, 2004. 